\title{
Chapter 11 \\ Nongovernment Organizations' Role \\ in Providing Quality School Education \\ in Pakistan: The Experiences of CARE \\ Foundation
}

\author{
Seema Aziz
}

Nongovernment organizations (NGOs) have played a crucial role in Pakistan since the country's independence in 1947 to assist in the establishment of the new government, mostly concentrating on rehabilitation and basic services (e.g., health and education). Since then, many NGOs have existed to champion human rights, and to cater to the poor and marginalized. ${ }^{1}$

\section{Issues and Challenges}

Pakistan faces significant challenges in providing access to education for its people. Aside from being among the countries with the world's highest out-of-school population, more than half of its adult population is unable to read and write. Latest data (2016-2017) also show that there are almost 22.5 million out-of-school children, with more girls than boys. These children do not go to school due to lack of access or because they do not see it worthwhile to pursue poor quality education. The Government of Pakistan attributes these poor education outcomes to low financing, inefficient budget spending, and weak management. ${ }^{2}$

Given these challenges, numerous NGOs have taken an active role in supporting the education sector. Many NGOs directly provide primary education in areas where

\footnotetext{
${ }^{1}$ Asian Development Bank. 1999. A Study of Nongovernment Organizations (NGOs) in Pakistan.

${ }^{2}$ Ministry of Federal Education and Professional Training 2018, Pakistan National Education Policy Framework 2018.
}

\section{S. Aziz (凶)}

CARE Foundation, Lahore, Pakistan

e-mail: seema@sefam.com 
there are no public or private schools, and give support for teacher training, curriculum development, and others. ${ }^{3}$

\section{Proposed Solutions}

In general, NGOs are encouraged to actively get involved and complement government initiatives. Particularly, NGOs have strengths in the areas of advocacy, service delivery, capacity building, grassroots community mobilization, innovation, social experimentation, and research. ${ }^{4}$ Such roles and areas of partnership have strong potential in aiding the Government to come up with replicable practices and innovative interventions to address education challenges in the country.

\section{CARE Foundation's Good Practices}

CARE Foundation Pakistan is a nonprofit organization that was founded in 1988 when the founder was visiting flood-affected areas to contribute to helping people rebuild their homes. CARE stands for cooperation for advancement, rehabilitation and education. It was established by first seeking donations from friends and family. The day CARE opened the first school's doors, 250 children were standing outside, waiting to be enrolled.

CARE is on a mission to provide every child in Pakistan with an equal opportunity and access to quality and marketable education. Education is a great equalizer, and it has the potential to reduce economic disparity within segments of the Pakistani population. CARE set up model schools in underdeveloped areas to provide children with equality of opportunity by providing education equal to the best schools in Pakistan.

In 1998, the local government approached CARE and requested it to adopt 10 government schools in failing condition. CARE transformed these schools by providing trained teachers and missing facilities and later took over another 180 government schools. CARE Foundation led the Government School Adoption Program in Pakistan and pioneered the public-private partnership model within $\mathrm{K}-10$ education. This was a unique partnership that helped provide quality education to the masses. Although faced with a lot of opposition from within the public school setup, this model turned out to be the most successful initiative to improve access and

\footnotetext{
${ }^{3}$ Shah, G.H., Bari, F. and Ejaz, N. 2005. The Role of NGOs in Basic and Primary Education. LUMS-McGill Social Enterprise Development Programme, 2005. ${ }^{4}$ ibid.
} 
quality of education throughout the country. CARE's public-private model has made a huge contribution toward improving education, as it is highly scalable, replicable, and cost-effective.

CARE Foundation brought a series of best practices to government schools by investing in infrastructure to ensure that children are provided with an environment conducive to learning. It transformed schools by building toilets, science laboratories, computer laboratories, libraries, and well-lit and ventilated classrooms, and it provided these schools with new furniture, clean drinking water, and proper sanitation. To inculcate and sustain the quality of education, CARE trained its own teachers, who later held training sessions for public school teachers to ensure that the curriculum being taught was comprehensive and the latest in $\mathrm{K}-10$ schooling. The quality of education had a tremendous effect on the nearby populations' willingness to send their children to the schools. Enrollment went up by $400 \%$, on average. CARE Foundation progressed from operating 10 government schools in 1998 to 855 schools by 2019, including double shift operations in 93 government schools to meet the increased demand. More than 285,000 students are currently studying in schools operated by CARE Foundation. In parallel, CARE also owns and operates 33 purpose-built schools today.

CARE runs the Teacher Training Program during the summer break, the winter break, and the induction period, wherein extensive training is provided. Under the CARE Teacher Training Program, the Foundation trains more than 7000 teachers on classroom management, activity-based learning, lesson planning, and more. Consequently, this helps teachers become more effective and empathetic educators.

In 1998, CARE Foundation felt that, while K-10 education is absolutely necessary, having a platform to attain university education definitely improves the odds of students successfully transitioning to the job market. The CARE Scholarship Program was introduced to offer a number of scholarships every year to bright and deserving students for university education. The 5000 recipients thus far have gone on to graduate from Pakistan's leading universities. The opportunity has been described as life-changing by these recipients. They become role models within their respective communities, encouraging more households to follow suit by committing to put their children through school and later university education.

With a focus on schools being the place where children's critical thinking and problem-solving and creative skills are nurtured, CARE also introduced several programs to meet the need. The Foundation provides its students with opportunities to learn new concepts, while enhancing an active interest in subjects that range from art to science, technology, and more.

For instance, CARE Foundation also implements the Access to English Language Program, launched in 2004, with the aim of developing English language skills in CARE schools. The Foundation currently has over 10,000 Access to English Language students enrolled in 280 CARE schools across Pakistan. On the other hand, CARE's Project-Based Learning Program fosters curiosity and promotes innovation. The program is centered on a specific theme each year. Students brainstorm and portray these themes through a spectrum of projects aimed at stimulating their critical thinking skills. 
Another program that is designed to catalyze students' critical and creative thinking skills, particularly through the arts, is the "Creativity, Culture and Education" program. The program is currently being run in 100 schools across Pakistan; 7000 students along with 140 teachers have participated in the program so far. One of our latest initiatives is the STEM program, which is designed to encourage experiential learning among our students from the inception of their schooling years. STEM is a curriculum based on the idea of educating students in four specific disciplinesscience, technology, engineering, and mathematics-through an interdisciplinary and applied approach. The CARE Alumni Network is also a major source of support for the alumni after they graduate. Resilience, strength, and courage are some key attributes CARE infuses in its students, which become core values as the students develop, enabling them to excel in their fields of interest.

After the first CARE school was set up in 1991, an industrial home was also set up to generate income opportunities for women affected by the devastating floods. The program has turned into a full-fledged enterprise development program known as CARE Crafts. The CARE Crafts project uses leftover textile pieces from local apparel houses to create accessories. The funds generated through this initiative are invested in CARE schools.

Education reduces poverty, boosts economic growth, encourages gender equality, and fosters peace. CARE Foundation's goal is to enroll 1 million children in our schools and provide them with an education on par with the best educational standards around the world.

\section{Application of These Good Practices}

CARE Foundation focuses on the quality of the basic education it provides. Instead of solely focusing on just building schools to reach poor and underprivileged children, CARE Foundation emphasizes ensuring quality education as a way of encouraging and keeping children in school. It recognizes that access/availability of schools is not sufficient to improve educational outcomes in Pakistan. The Foundation operates under the principle that student enrollment will improve if we raise the quality of education, even if we do not provide scholarships or financial assistance.

The CARE Foundation model also makes sure to consider culture and values in carrying out its curriculum and other programs. For instance, aside from providing quality education among Pakistani children, what is noteworthy about CARE Foundation is that it ensures an encouraging environment, and fosters creative and innovative approaches to learning. CARE believes that "it is more important how much the teacher cares, more than what the teacher knows."

CARE Foundation has not only improved enrollment, cohort survival rates, and quality of schools; it also promotes socioemotional or soft skills, which are deemed crucial in preparing children for the future world of work. Overall, CARE has been able to use its strategic strengths and expertise as an NGO (i.e., advocacy, service 
delivery, capacity building, grassroots community mobilization, innovation, social experimentation, and research) to come up with successful practices that complement and improve government education programs.

\section{Implications for the Future}

As rapid technology adoption is transforming skills requirements globally, it is imperative for education systems to ensure that children are well prepared to keep up with the pace of the changing world of work. Learners need to be equipped with skills that cannot easily be automated, such as ability to collaborate, communicate, and solve problems. These twenty-first-century skills are developed through social and emotional learning, ${ }^{5}$ which the CARE Foundation model already integrates in its curriculum and teaching methodologies.

This model is cost-efficient and easy to replicate. However, such an approach entails consistent internal monitoring and evaluation for growth and replication. Sustained support from government and the private sector would also significantly help scale up and sustain such practices.

\section{Conclusion}

Given NGOs' strengths in performing various roles to contribute to society, they are key players in championing and achieving basic education reforms. Their nature as NGOs gives them strengths and strategic opportunities to come up with innovative practices that can help achieve desired outcomes and goals in education.

CARE Foundation's model schools in disadvantaged and underdeveloped areas in Pakistan have shown positive results. Enrollments in CARE schools have increased and some schools have even started running in double shifts. Subsequently, more schools in other rural areas were opened. These successes have motivated the Pakistan Government to collaborate and pursue public-private partnerships. Although initially faced with resistance and opposition within the system, this collaboration has notably contributed to increased access and improved quality of education in Pakistan. CARE was not only able to help in ensuring adequate infrastructure in government schools, but also in teacher training and curriculum improvement.

While such education initiatives from the private sector and civil society are easy to replicate, strong partnership with government will be crucial in ensuring success, as observed in the experience of CARE Foundation. Close cooperation among government, civil society, the private sector, and communities is instrumental

\footnotetext{
${ }^{5}$ World Economic Forum. 2016, March. What are the twenty-first-century skills every student needs? WEF Website, Retrieved from http://www.weforum.org/agenda/2016/21st-century-skillsfuture-jobs-students.
} 
in identifying the challenges and needs of the education system to ensure that the right issues are being addressed. Such cooperation also facilitates productive and efficient pooling of resources, as well as complementation of programs being implemented by different stakeholders.

Link to the presentation material: https://events.development.asia/materials/201 71212/care-foundation-changing-lives-through-education.

\section{References}

Asian Development Bank. (1999). A study of Nongovernment Organizations (NGOs) in Pakistan. Aziz, S. (2017, December). The CARE Foundation. Presented at the ADB 7th International Skills Forum: Anticipating and Preparing for Emerging Skills and Jobs. Manila, Philippines.

CARE Foundation. (n.d). CARE Story. Retrieved from CARE Foundation Website https://carepa kistan.org/about/.

Ministry of Federal Education and Professional Training. (2018). Pakistan National Education Policy Framework 2018.

Shah, G. H., Bari, F., \& Ejaz, N. (2005). The role of NGOs in basic and primary education. LUMSMcGill Social Enterprise Development Programme.

World Economic Forum. (2016, March). What are the 21st-century skills every student needs? WEF Website, Retrieved from http://www.weforum.org/agenda/2016/21st-century-skills-future-jobsstudents.

The views expressed in this Chapter are those of the authors and do not necessarily reflect the views and policies of the Asian Development Bank (ADB) or its Board of Governors or the governments they represent.

ADB does not guarantee the accuracy of the data included in this Chapter and accepts no responsibility for any consequence of their use. The mention of specific companies or products of manufacturers does not imply that they are endorsed or recommended by ADB in preference to others of a similar nature that are not mentioned.

By making any designation of or reference to a particular territory or geographic area, or by using the term "country" in this Chapter, ADB does not intend to make any judgments as to the legal or other status of any territory or area.

This work is available under the Creative Commons Attribution 3.0 IGO license (CC BY 3.0 IGO) https://creativecommons.org/licenses/by/3.0/igo/. By using the content of this Chapter, you agree to be bound by the terms of this license. For attribution, translations, adaptations, and permissions, please read the provisions and terms of use at https://www.adb.org/terms-use\#openac cess.

This CC license does not apply to non-ADB copyright materials in this Chapter. If the material is attributed to another source, please contact the copyright owner or publisher of that source for permission to reproduce it. ADB cannot be held liable for any claims that arise as a result of your use of the material.

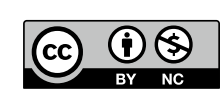

